\title{
HLA-A2 and -A24-restricted glypican-3-derived peptide vaccine induces specific CTLs: Preclinical study using mice
}

\author{
YUTAKA MOTOMURA ${ }^{1}$, YOSHIAKI IKUTA ${ }^{3,4}$, TOSHIMITSU KURONUMA ${ }^{1}$, HIROYUKI KOMORI ${ }^{3,4}$, \\ MASAAKI ITO ${ }^{2}$, MASAMI TSUCHIHARA ${ }^{1}$, YOSHIYUKI TSUNODA ${ }^{2}$, HIROFUMI SHIRAKAWA ${ }^{1,2}$, \\ HIDEO BABA $^{3}$, YASUHARU NISHIMURA $^{3}$, TAIRA KINOSHITA $^{2}$ and TETSUYA NAKATSURA ${ }^{1}$ \\ ${ }^{1}$ Cancer Immunotherapy Project, Investigative Treatment Division, Research Center for Innovative Oncology, \\ and ${ }^{2}$ Surgery Division, National Cancer Center Hospital East, 6-5-1 Kashiwanoha, Kashiwa 277-8577; \\ Departments of ${ }^{3}$ Immunogenetics, ${ }^{4}$ Gastroenterology and Hepatology, Graduate School of Medical Sciences, \\ Kumamoto University, 1-1-1 Honjo, Kumamoto 860-8556, Japan
}

Received December 10, 2007; Accepted January 28, 2008

\begin{abstract}
We previously reported that glypican-3 (GPC3) is uniquely overexpressed in human hepatocellular carcinoma and melanoma and that it is an ideal tumor antigen for immunotherapy in mouse models. We recently identified both HLA-A24 ( $\left.A^{*} 2402\right)$ and $\mathrm{H}-2 \mathrm{~K}^{\mathrm{d}}$-restricted $\mathrm{GPC} 3_{298-306}$ (EYILSLEEL) and HLA-A2 ( $\left.A^{*} 0201\right)$-restricted GPC $3_{144-152}$ (FVGEFFTDV), both of which can induce GPC3-reactive cytotoxic T cells (CTLs). The present study was a preclinical study in a mouse model that was conducted in order to design an optimal schedule for clinical trial of GPC3-derived peptide vaccine. When $\mathrm{BALB} / \mathrm{c}$ mice were intradermally vaccinated at the base of the tail with $\mathrm{K}^{\mathrm{d}}$-restricted $\mathrm{GPC}_{298-306}$ peptide mixed with incomplete Freund's adjuvant (IFA), the peptidespecific CTLs were induced. But the peptide alone could not induce peptide-specific $\mathrm{CD} 8^{+} \mathrm{T}$ cells. Furthermore, proteomic analyses showed that IFA protected the peptide against degradation in the human serum. Peptide-reactive CTLs were induced by peptide vaccine in a dose-dependent manner. In addition, at least two vaccinations with a single dose $>10 \mu \mathrm{g}$ were needed for the induction of $\mathrm{GPC}_{298-306^{-}}$ specific CTLs. But repeated vaccination with a lower dose of GPC $3_{298-306}$ did not induce peptide-specific CTLs. Similarly, induction of an Ag-specific immune response by HLA-A2
\end{abstract}

Correspondence to: Dr Tetsuya Nakatsura, Cancer Immunotherapy Project, Investigative Treatment Division, Research Center for Innovative Oncology, National Cancer Center Hospital East, 6-5-1 Kashiwanoha, Kashiwa 277-8577, Japan

E-mail: tnakatsu@east.ncc.go.jp

Abbreviations: BM-DC, bone marrow-derived dendritic cell; $\mathrm{mAb}$, monoclonal antibody; M/W, molecular/weight

Key words: cancer immunotherapy, GPC3, peptide vaccine, hepatocellular carcinoma
GPC $3_{144-152}$ depended on the dose administered. The results of this study suggested that IFA is one of the indispensable adjuvants for peptide-based immunotherapy, and that the immunological effect of peptide vaccines depends on the dose of peptide injected.

\section{Introduction}

Hepatocellular carcinoma (HCC) is one of the most common tumors worldwide, especially in Asian and Western countries (1). Despite advances in diagnosis and treatment, the overall survival of patients with HCC has not significantly improved in the last two decades (2). The effective treatments currently available are only indicated in a relatively small proportion of early stage cases. When patients presents with clinical manifestations of HCC, the tumor is usually advanced, and there are few treatment options. Many HCC patients have type $\mathrm{B}$ or $\mathrm{C}$ hepatitis or cirrhosis, so patients treated surgically or by other therapies are also at high risk for recurrence. Furthermore, the liver function of such patients is often very poor, so treatment for recurrence is often restricted. As a result, the prognosis of HCC remains poor and new therapies for cancer development and recurrence, i.e., adjuvant therapy, are urgently needed.

We previously reported that glypican-3 (GPC3), glycosylphosphatidylinositol (GPI)-anchored membrane protein, is specifically overexpressed in human HCC and melanoma, and that among normal tissues it is slightly expressed in placenta and embryonic liver (3). We found that GPC3 is useful not only as a novel tumor marker, but also as a target antigen for immunotherapy in several studies with mice $(4,5)$. In addition, we identified CTL epitope peptides: HLA-A24-restricted GPC3 $3_{298-306}$ (EYILSLEEL) and HLAA2-restricted GPC3 ${ }_{144-152}$ (FVGEFFTDV) (6). To design the schedule for the phase I clinical study of these GPC3-derived peptide vaccines, many factors need to be taken into consideration: the adjuvant, dosage, number of doses, vaccination interval, etc. Many investigators have reported various vaccination schedules $(7,8)$. There is no world-wide consensus concerning the schedule to use for administration of peptide 
vaccines. In this study, we attempted to identify a more effective vaccine regimen that would induce a strong cellmediated immune response. Ten years ago Salgaller et al reported that they did not observe any dose dependency between 1 and $10 \mathrm{mg}$ in the capacity of gp100 peptide to enhance immunogenicity in humans (9). The results of our present study, however, showed dose-dependency in the immunizing effect of a peptide vaccine.

\section{Materials and methods}

Mice. Female BALB/c mice at 6-8 weeks of age were obtained from Japan SLC (Hamamatsu, Japan) or Charles River Laboratories. HLA-A2.1 (HHD) Tgm; H-2D b-l-h2m-/ double knockout mice transfected with a human h2m-HLA$A 2.1$ (a1 a2)- $H-2 D^{\mathrm{b}}$ (a3 transmembrane cytoplasmic) (HHD) monochain construct gene were prepared in the Department SIDA-Retrovirus, Unité d'Immunité Cellulaire Antivirale, Institut Pasteur, France (10), and kindly provided by Dr F.A. Lemonnier. The mice were maintained under specificpathogen-free conditions. The mouse experiments were approved by the Animal Research Committee of the National Cancer Center Hospital East.

Cells lines. A subline of BALB/c-derived colorectal adenocarcinoma cell line Colon 26, C26 (C20) (11) was provided by Dr Kyoichi Shimomura (Astellas Pharmaceutical Co., Tokyo, Japan). Colon 26/GPC3 (C26/GPC3) is an established stable GPC3-expressing cell line (4). RMA-HHD cells were kindly provided by Dr Masanori Matsui of Saitama Medical School, Saitama, Japan. A human B2m-HLA-A2.1 ( $\alpha 1 \alpha 2)$ $\mathrm{H}-2 \mathrm{D}^{\mathrm{b}}$ ( $\alpha 3$ transmembrane cytoplasmic) (HHD) monochain construct was transfected into RMA lymphoma cells [transporter associated with antigen presentation (TAP) positive] to establish RMA-HHD cells (10). The cells were cultured in RPMI-1640 medium supplemented with 10\% FCS. To obtain GPC3-expressing RMA-HHD (RMA-HHD-GPC3) cells, RMA-HHD cells were transfected with pCAGGS-GPC3internal ribosomal entry site (IRES)-puromycin-resistant gene with Lipofectamine 2000 reagent (Invitrogen Corp., Carlsbad, CA), selected with puromycin, and then subjected to cloning by limiting dilution in drug-free medium in 96well culture plates $(12,13)$. Dendritic cells were obtained from bone marrow cells (BM-DCs) as described previously (4). Irradiated BM-DCs pulsed with peptide were used for in vitro CTL culture or as target cells for Elispot assays.

Vaccination. HLA-A24- and $\mathrm{K}^{\mathrm{d}}$-restricted GPC $3_{298-306}$ (EYILSLEEL) and HLA-A2-restricted GPC3 $3_{144-152}$ (FVGEFFTDV) were dissolved in $7 \% \mathrm{NaHCO}_{3}$ and the solution was diluted with saline. For peptide vaccination, mice were intradermally injected at the base of the tail with peptide solution emulsified in incomplete Freund's adjuvant (IFA). Different doses of peptide were administered at 7-day intervals, and mice were sacrificed to obtain inguinal lymphocytes and spleen cells seven days after the final vaccination.

IFN- $\gamma$ Elispot assays. Female BALB/c mice were intradermally vaccinated with $\mathrm{GPC}_{298-306}$ or $\mathrm{GPC} 3_{144-152} / \mathrm{IFA}$.
Their inguinal lymphocytes were stimulated with peptidepulsed BM-DCs in vitro for five days. The proportion of cells producing IFN- $\gamma$ against target cells (BM-DCs pulsed with or without GPC3 peptide) was assessed by an Elispot assay as described previously (14). The spots were automatically counted and subsequently analyzed with the Eliphoto system (Minerva Tech, Tokyo, Japan).

Analysis of peptide degradation. GPC $3_{298-306}$ was mixed with human serum, and the solution was applied to the surfaces of a Q10 (strong anion exchange) ProteinChip (Bio-Rad Laboratories, CA). We sequentially examined the solution with a SELDI-TOF mass spectrometer (Bio$\mathrm{Rad})$. Female BALB/c mice were intradermally vaccinated with $\mathrm{GPC} 3_{298-306} / \mathrm{IFA}$ at the base of the tail. A week later, we collected the residual peptide vaccine at the base of the tail into buffer in a tube, and the tube was centrifuged at $4^{\circ} \mathrm{C}$ at $10,000 \mathrm{rpm}$ for $15 \mathrm{~min}$. The supernatant was applied to a ProteinChip and the surface of the chip was examined with the spectrometer.

Induction of GPC3-specific CTLs and cytotoxicity assay. Mice were intradermally vaccinated twice with $50 \mu \mathrm{g}$ GPC3 peptide/IFA 7 days apart. Seven days after the second vaccination, inguinal lymph nodes were excised and the lymphocytes were cultured in 24-well culture plates $\left(5 \times 10^{6}\right.$ per well) with GPC3 peptide-pulsed BM-DCs $\left(1 \times 10^{5}\right.$ per well) in RPMI medium supplemented with $10 \%$ horse serum, recombinant human interleukin (IL)-2 (100 units/ml), and 2-mercaptoethanol $(50 \mu \mathrm{mol} / \mathrm{l})$. After culture for 5 days, the cells were recovered and analyzed for their cytotoxic activity against target cells with the TERASCAN VPC system (Minerva Tech) as previously described (15). Briefly, C26, C26/GPC3, RMA-HHD and RMA-HHD-GPC3 cells were used as target cells and labeled with calcein-AM solution for $30 \mathrm{~min}$ at $37^{\circ} \mathrm{C}$. The labeled cells were washed three times and distributed to the 96 -well culture plate $\left(1 \times 10^{4}\right.$ per well), and they were then incubated with effector cells for 5-6 h. Fluorescent intensity was measured before and after the 5-6-h culture, and Ag-specific cytotoxic activity was calculated by using this formula: cytotoxicity $(\%)=[$ (sample release $)$ (spontaneous release)]/[(maximum release) - (spontaneous release)] x 100. In some experiments, $\mathrm{CD}^{+} \mathrm{T}$ cells were isolated from effector cell preparations with a magnetic cell sorting system (Miltenyi, Bergisch Gladbach, Germany). Positively selected CD8 ${ }^{+} \mathrm{T}$ cells were $95 \%$ pure as determined by flow cytometry.

Histologic and immunohistochemical analysis. Mice were injected twice with GPC3 peptide vaccine, and seven days later tumor cells were subcutaneously implanted in their shaved backs. Seven days after the tumor challenge, frozen sections of tumor tissue were prepared. The frozen tissue sections were immunohistochemically analyzed using monoclonal antibody (mAb) specific for CD4 (L3T4; BD PharMingen, San Diego, CA) or CD8 (Ly-2; BD PharMingen) as described previously (4).

Statistical analysis. The 2-tailed Student's t-test was used to determine the statistical significance of differences in the 
data obtained by ELISPOT assay. $\mathrm{P}<0.05$ was considered to be significant. Statistical analyses were made using the StatView 5.0 software package (Abacus Concepts, Calabasas, CA).

\section{Results}

IFA is an effective adjuvant for the peptide vaccine that induced strong immune responses and maintained the stability of the peptide. We attempted to verify whether emulsions of GPC3 peptide in IFA could induce a peptidespecific immune response in mouse models. The results showed that only GPC3 peptide emulsified in IFA elicited a T-cell-mediated immune response, whereas vaccination with peptide alone failed to induce any detectable immune response (Fig. 1A). In addition, we investigated the stability of GPC3 peptide alone in human serum, with the Surface Enhanced Laser Desorption/Ionization SELDI system (BioRad). We applied the sample of GPC3 peptide mixed with human serum to a ProteinChip and detected the peak of GPC3 peptide. The peak value of $\mathrm{GPC}_{298-306}$ in buffer was about 1,000 , whereas the peak of GPC $3_{298-306}$ in serum had decreased to 200,3 min after mixing it with the serum (Fig. 1B). This finding indicated that GPC3 peptide was immediately degraded in serum. Moreover, we collected the white residue of peptide/IFA emulsions that were still present at the base of the tail of the vaccinated mice, and after applying the peptide/IFA emulsions to a ProteinChip, quantified the peak of GPC $3_{298-306}$. Mass spectrometric analysis demonstrated that the peptide was still present in a stable form in the peptide/IFA emulsions (Fig. 1C). IFA not only induced a potent immune response, but protected the peptide from various enzymes in the serum.

Dose-dependent effects of GPC3-derived peptide vaccine emulsified in IFA. Next we examined whether a more peptide-specific response was induced, when a higher dose of peptide was used. The proportion of peptide-specific CTLs among $5 \times 10^{4} \mathrm{CD} 8^{+} \mathrm{T}$ cells was evaluated by IFN- $\gamma$ Elispot assays, when mice were vaccinated with $\mathrm{GPC} 3_{298-306}$ $\mathrm{K}^{\mathrm{d}}$-restricted peptide doses of $5,10,20$, or $50 \mu \mathrm{g}$. Peptidespecific $\mathrm{CD}^{+} \mathrm{T}$ cell responses were observed when vaccinated with $\mathrm{GPC} 3_{298-306} \mathrm{~K}^{\mathrm{d}}$-restricted peptide doses above $10 \mu \mathrm{g}$ (Fig. 2A). Additionally, as the peptide dose increased, peptide reactive CTLs were detected more frequently (Fig. 2A). We vaccinated A2 Tg mice with HLA-A2restricted GPC $3_{144-152}$ peptide in the same manner. The results indicated that the higher doses of the peptide induced a greater peptide-specific immune response (Fig. 2B). We therefore, concluded that the higher the dose of peptide injected, the more peptide-specific $\mathrm{CD}^{+} \mathrm{T}$ cells were induced. But Elispots by vaccinations of $>5 \mu \mathrm{g} \mathrm{GPC} 3_{144-152}$ been seen to reach a plateau level.

Marked infiltration of subcutaneous tumor tissue by $C D 8^{+} T$ cells in mice vaccinated with the $50 \mu \mathrm{g}$ dose of GPC3 peptide. Immunohistochemical analysis of the tumor tissue specimens showed more intense infiltration by $\mathrm{CD}^{+} \mathrm{T}$ cells, but not by $\mathrm{CD}^{+} \mathrm{T}$ cells, in and/or around C26/GPC3 (Fig. 3D) or RMA-
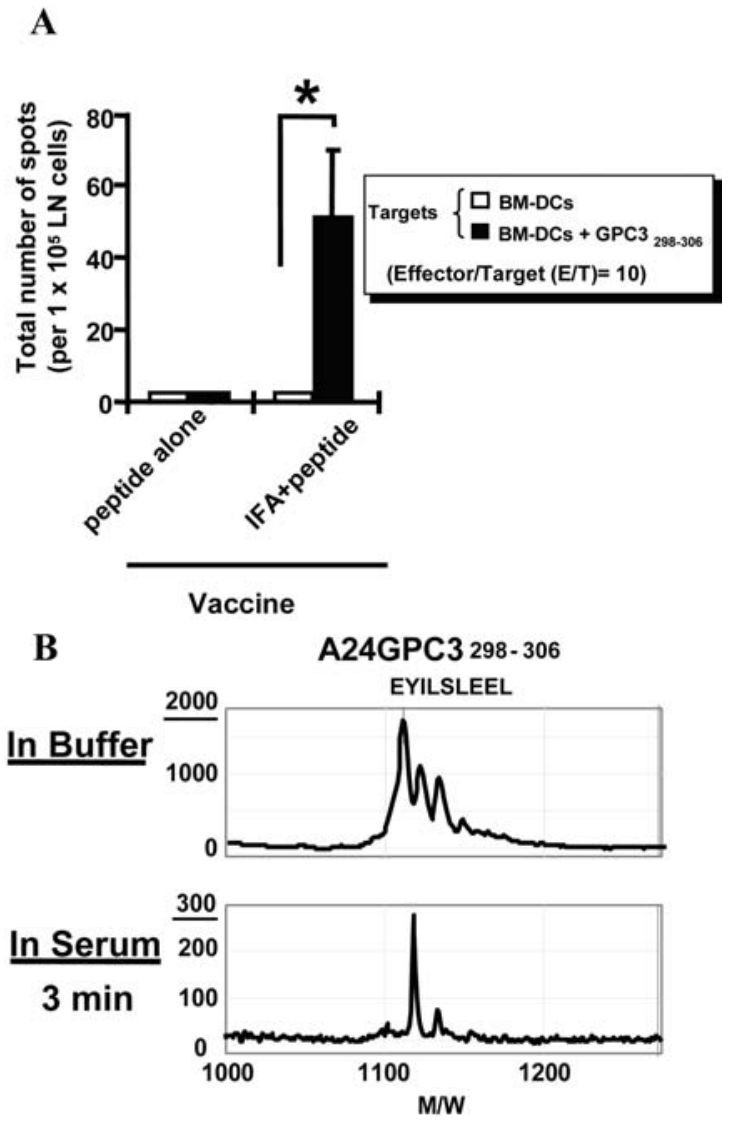

C

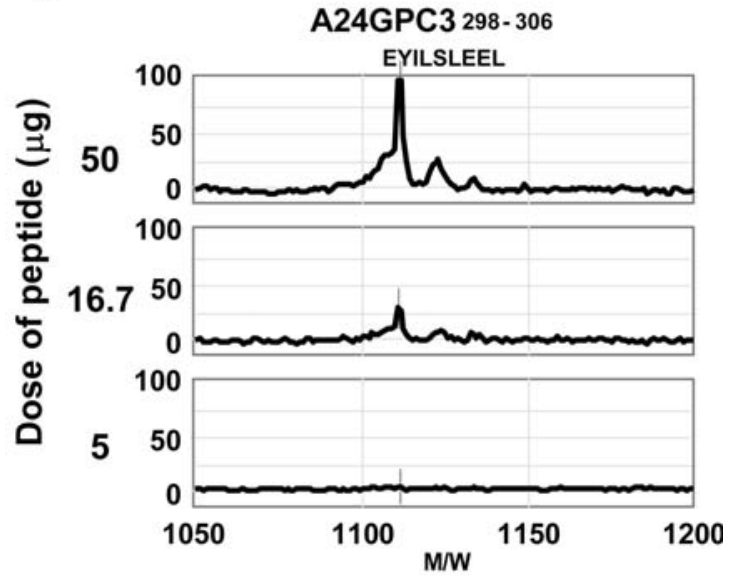

Figure 1. IFA is an appropriate adjuvant for the peptide vaccine. (A) The GPC $3_{298-306}$-specific immune response was induced by peptide emulsified in IFA. Female BALB/c mice were vaccinated twice by intradermal injection of $50 \mu \mathrm{g}$ of GPC $3_{298-306}$ (EYILSLEEL) with IFA. Seven days after the second injection, inguinal lymph node cells were isolated and cultured with GPC $3_{298-306}$-pulsed BM-DCs for 5 days. The cells were recovered, and their Ag-specific activity was analyzed by IFN- $\gamma$ Elispot assays against BM-DCs pulsed or not pulsed with $\mathrm{GPC} 3_{298-306} \cdot{ }^{*} \mathrm{P}<0.05$, statistically significant difference in response. (B) Stability of GPC $3_{298-306}$ (EYILSLEEL) in human serum. We measured $\mathrm{GPC}_{298-306}$ in the human serum 3 min after the mixture of GPC $3_{298-306}$ and human serum by SELDI-TOF mass spectrometry. The discriminating peaks of M/W 1111 represent GPC $3_{298-306}$. When GPC3 peptide was mixed with human serum, the peptide was immediately degraded by various proteases. (C) Detection of GPC3 peptide in emulsions collected from vaccinated mice. BALB/c mice were intradermally injected at the base of the tail with GPC $3_{298-306}$ emulsified in IFA. A week later we collected peptide/IFA emulsions at the base of the tail and measured GPC3 peptide contained in the emulsions. When injected with $50 \mu \mathrm{g}$ of peptide, GPC3 peptide was detected clearly. Data are representative of 3 independent experiments with similar results in (A-C). 
A

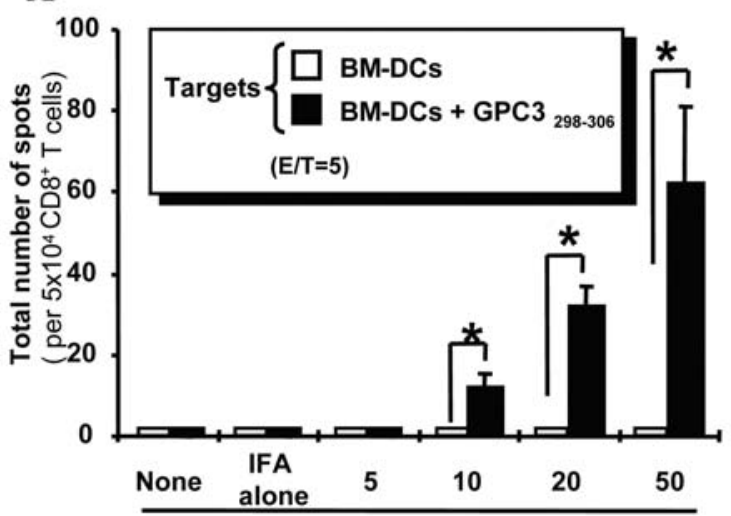

Dose of peptide $(\mu \mathrm{g})$

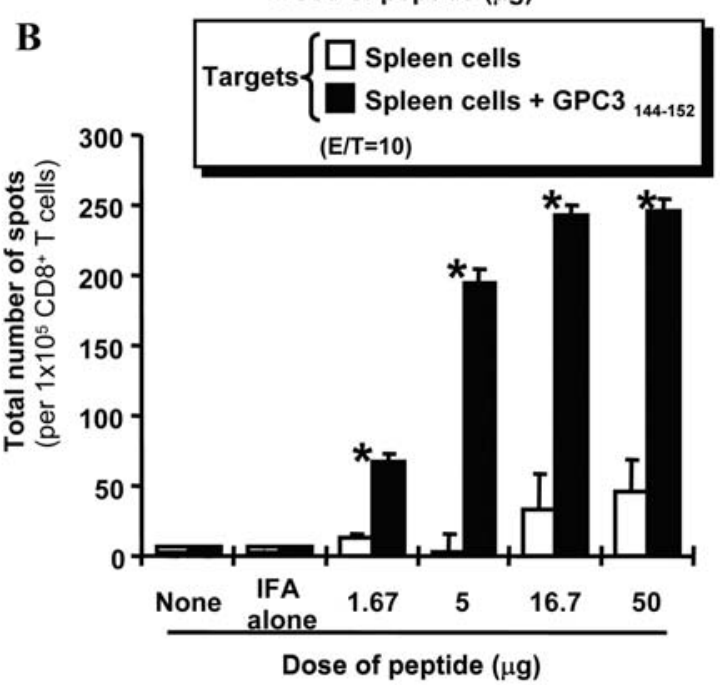

Figure 2. The higher the dose of peptide injected, the more peptide-specific $\mathrm{CD}^{+} \mathrm{T}$ cells were induced. Groups of mice were vaccinated twice at 7-day intervals with one of the dose levels of $\mathrm{H}-2 \mathrm{~K}^{\mathrm{d}}$-restricted $\mathrm{GPC} 3_{298-306}$ peptide (A) or HLA-A2-restricted GPC $3_{144-152}$ peptide (B) emulsified with IFA (each group; $\mathrm{n}=3$ ). Inguinal lymphocytes were restimulated in vitro with each GPC3 peptide-pulsed BM-DCs for 5 days. The recovered cells were sorted to the $\mathrm{CD}^{+} \mathrm{T}$ cells fraction by MACS and IFN- $\gamma$ Elispot assays were performed. Peptide-specific CD $8^{+} \mathrm{T}$ cells were induced dose-dependently. Data are representative of 3 independent experiments with similar results. ${ }^{*} \mathrm{P}<0.05$, difference in response was statistically significant.

HHD-GPC3 (Fig. 3H) tumor tissue of mice vaccinated with the $50 \mu \mathrm{g}$ dose of GPC3 peptide than with IFA alone, and the $1.67 \mu \mathrm{g}$ dose of GPC3 peptide (Fig. 3). This phenomenon was also observed in metastatic inguinal lymph nodes tissues (data not shown). These results also suggest that the higher the dose of peptide, the more peptidespecific $\mathrm{CD}^{+} \mathrm{T}$ cells were induced and infiltrated the GPC3expressing tumor. However, $1.67 \mu \mathrm{g}$ dose of GPC $3_{144-152}$ had seemed to induce a few peptide-specific $\mathrm{CD}^{+} \mathrm{T}$ cells, which corresponded to the result shown in Fig. $2 \mathrm{~B}$.

A second vaccination is needed to induce a peptide-specific response. Next we attempted to determine how many vaccinations were required to induce a peptide-specific immunological response. BALB/c mice were vaccinated with a $1.67,5,16.7,50 \mu \mathrm{g}$ dose of peptide once a week for 1-4 weeks, respectively. A single vaccination did not elicit a peptide-specific immune response at any of the

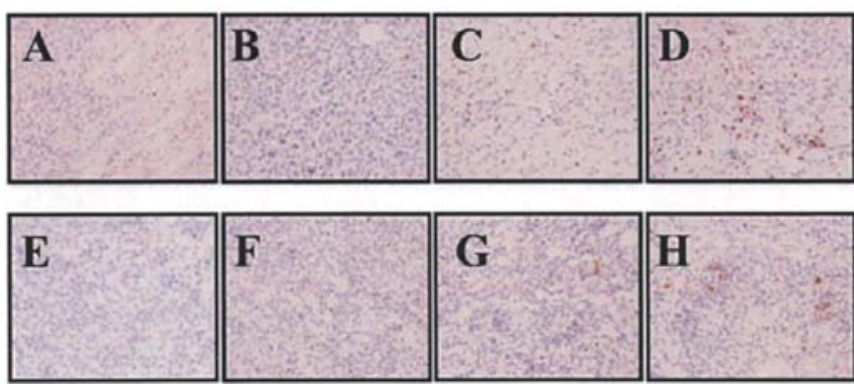

Figure 3. Infiltration by $\mathrm{CD}^{+} \mathrm{T}$ cells around and into subcutaneous C26/GPC3 (A-D) or RMA-HHD-GPC3 (E-H) tumor tissue is shown. We estimated infiltration by $\mathrm{CD}^{+} \mathrm{T}$ cells immunohistochemically; no treatment (A and E), IFA (B and F), $1.67 \mu \mathrm{g}$ (C), $50 \mu \mathrm{g}$ (D) of GPC3 ${ }_{298-306}$, $1.67 \mu \mathrm{g}(\mathrm{G}), 50 \mu \mathrm{g}(\mathrm{H})$ of $\mathrm{GPC} 3_{144-152}$. In mice treated with $50 \mu \mathrm{g}$ GPC3 peptide, a larger number of $\mathrm{CD}^{+} \mathrm{T}$ cells had clearly infiltrated into and/or around the tumor (D and H). But even in $1.67 \mu \mathrm{g}$ dose of $\mathrm{GPC} 3_{144-152}$, a few peptide-specific $\mathrm{CD}^{+} \mathrm{T}$ cells were induced (original magnification, $\mathrm{x} 200)$.

GPC $3_{298-306}$ dose levels (Fig. 4A). Induction of a peptidespecific $\mathrm{T}$-cell response required at least two vaccinations and $>16.7 \mu \mathrm{g}$ dose of peptide, and no expansion of peptidespecific $\mathrm{T}$ cells occurred after repeated vaccinations with lower doses of peptide (Fig. 4B-D). We also compared immunological responses induced by two and five vaccinations, with 1.67 and $50 \mu \mathrm{g}$ doses of HLA-A2 GPC $3_{144-152}$, but the same as with HLA-A24 GPC $3_{298-306}$, five vaccinations did not increase a peptide-specific response (Fig. 5).

Cytotoxity of $C D 8^{+} T$ cells primed with GPC3 peptide vaccines. We analyzed the cytotoxity of $\mathrm{CD}^{+} \mathrm{T}$ cells primed with GPC3 peptide vaccines. Their killing activity against target cells that expressed or did not express GPC3 was analyzed. The effector cells primed with the GPC3 vaccines showed a significantly higher killing activity against C26/ GPC3 cells than against C26 cells, and significantly higher killing activity against RMA-HHD-GPC3 cells than against untransfected RMA-HHD cells (Fig. 6). These results suggest that the $\mathrm{CD} 8^{+} \mathrm{T}$ cells induced by GPC3 peptide vaccinations have cytotoxic activity against tumor cells that express GPC3 naturally.

\section{Discussion}

The stability of antigens and the immunogenicity of ISA 720 based on Western blot experiments (16) have been verified, and in the present study we showed that IFA is one of the indispensable adjuvants for peptide vaccines.

We previously reported that vaccination with $\mathrm{GPC} 3_{298-306}$ peptide-pulsed BM-DCs induced complete rejection of a C26/GPC3 tumor challenge in a mouse model (4), but in the present study, C26/GPC3 tumors in a prophylactic model were not rejected after two intradermal vaccinations with GPC3 peptide/IFA at the base of the tail even though $\mathrm{CD}^{+} \mathrm{T}$ cells by GPC3 peptide vaccine was demonstrated by immunological and immunohistological analysis (data not shown). Comparison of the capacity of peptide-pulsed BMDCs vaccine to induce peptide-specific CTLs with the 


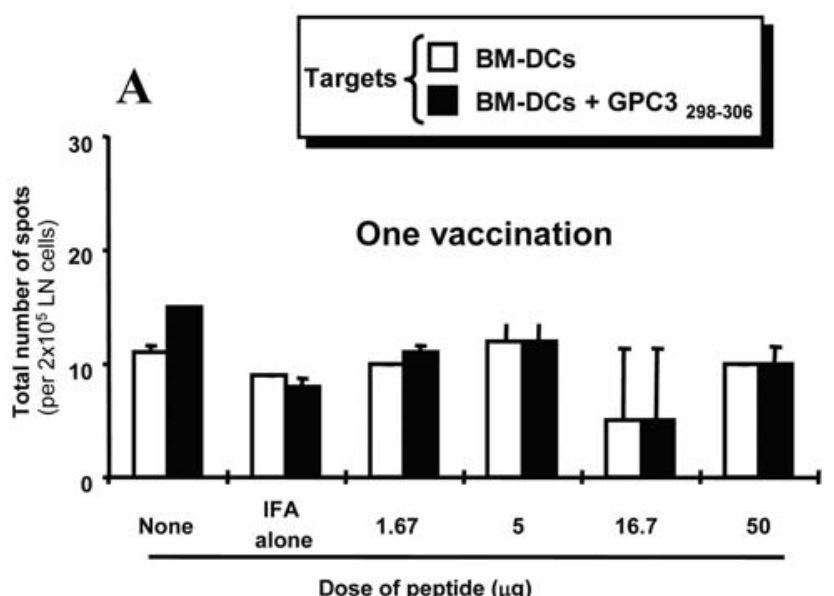

B

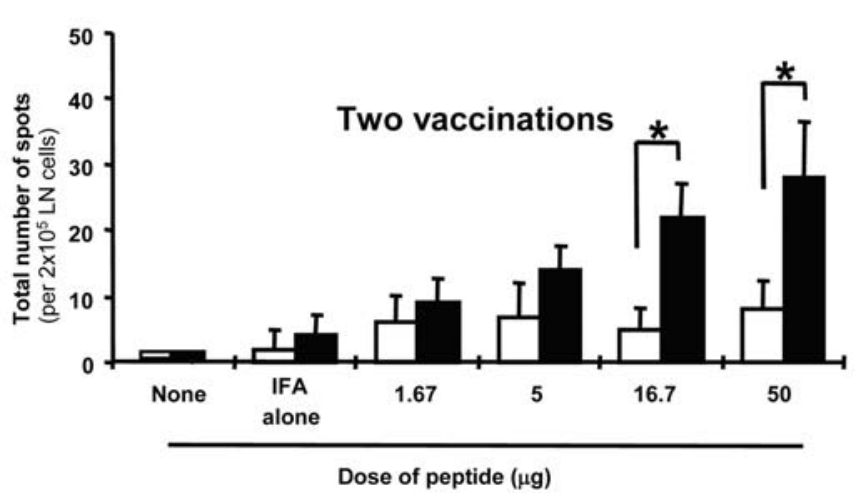

C

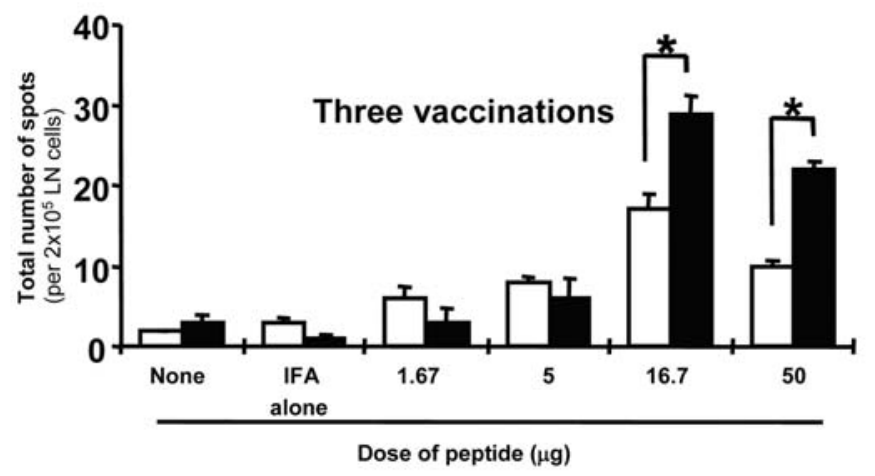

D

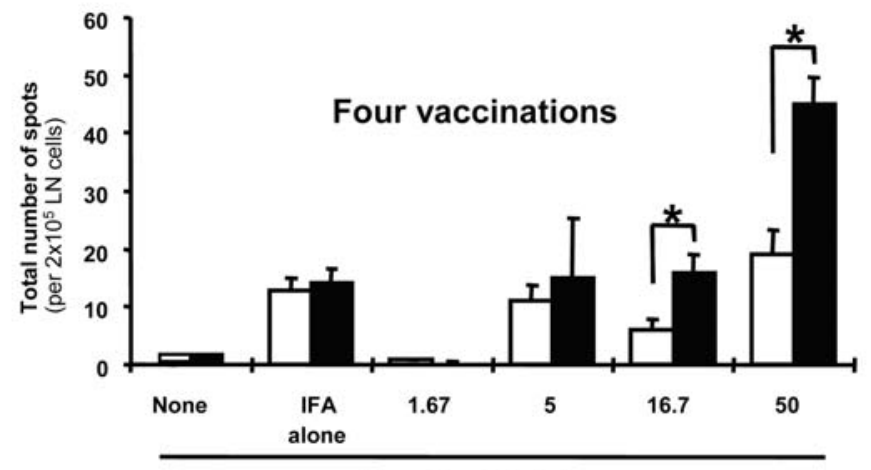

Dose of peptide $(\mu \mathrm{g})$

Figure 4. A second vaccination is needed to induce peptide-specific T cells. The immune responses to one (A), two (B), three (C) and four (D) vaccinations with each dose of peptide are shown. BALB/c mice (each group: $\mathrm{n}=3$ ) were vaccinated with $1.67,5,16.7$, or $50 \mu \mathrm{g} \mathrm{GPC} 3_{298-306}$. Seven days after the final vaccination, bilateral inguinal LNs were excised. Each lymphocyte was restimulated in vitro with $\mathrm{GPC}_{298-306}$ peptide-pulsed BM-DCs for 5 days, and IFN- $\gamma$ Elispot assays were then performed against BM-DCs pulsed or not pulsed with GPC $3_{298-306}$ to count GPC $3_{298-306}$ peptide-specific CTLs. Data are representative of 3 independent experiments with similar results (A-D).

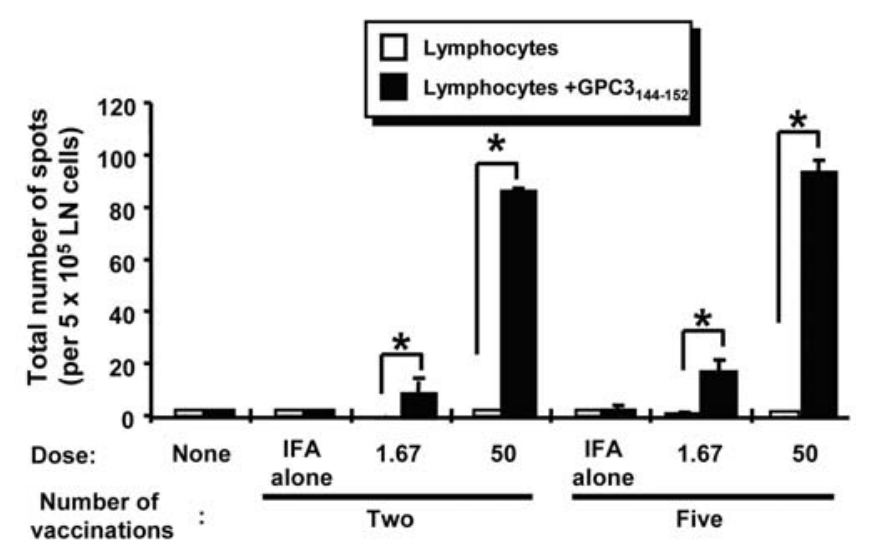

Figure 5. Comparison of immune responses after two or five vaccinations with a $1.67 \mu \mathrm{g}$ or $50 \mu \mathrm{g}$ dose of $\mathrm{GPC}_{144-152}$. A2 $\mathrm{Tg}$ mice $(\mathrm{n}=3)$ were vaccinated with $1.67 \mu \mathrm{g}$ or $50 \mu \mathrm{g} \mathrm{GPC} 3_{144-152}$ in the same manner in Fig. 3, but the IFN- $\gamma$ Elispot assay was performed using whole lymph node cells without in vitro culture. Data are representative of 3 independent experiments with similar results. ${ }^{*} \mathrm{P}<0.05$, difference in response was statistically significant.

capacity of peptide/IFA vaccine by in vitro IFN- $\gamma$ Elispot assays demonstrated that peptide-pulsed BM-DCs vaccine induced more peptide-specific CTLs (data not shown). There have been few reports of induction of tumor regression in vivo by peptide vaccine. Pilar et al recently reported finding that a combination of peptide vaccine and $\mathrm{CpG}$ induced stronger anticancer responses not only in a prophylactic model, but also in a therapeutic model. They reported in the same study that vaccination with peptide p66 in IFA in the absence of CpG resulted in insignificant CTL responses (17). Although other adjuvants, including $\mathrm{CpG}$, were not effective in the present study (data not shown), peptide/IFA with $\mathrm{CpG}$ may be effective. Further study is needed.

The results of the present study showed that at least two vaccinations were necessary to elicit immunological effects. A comparison between HLA-A2-restricted GPC $3_{144-152} /$ IFA and $\mathrm{K}^{\mathrm{d}}$-restricted GPC $3_{298-306}$ showed that GPC $3_{144-152}$ induced more peptide-specific CTLs at a lower dose. Moreover, HLA-A2-restricted GPC $3_{144-152}$ specific CTLs were induced without in vitro stimulation with $\mathrm{GPC}_{144-152}$ peptide. That may have been attributable to the difference in mouse strain. It is usually said that $\mathrm{C} 57 \mathrm{BL} / 6$ and $\mathrm{BALB} / \mathrm{c}$ mice are a prototypical Th1-type strain and a prototypical Th2type mouse strain, respectively $(18,19)$ and the difference in genetic background seemed to affect their susceptibility to each of the peptide vaccines. 

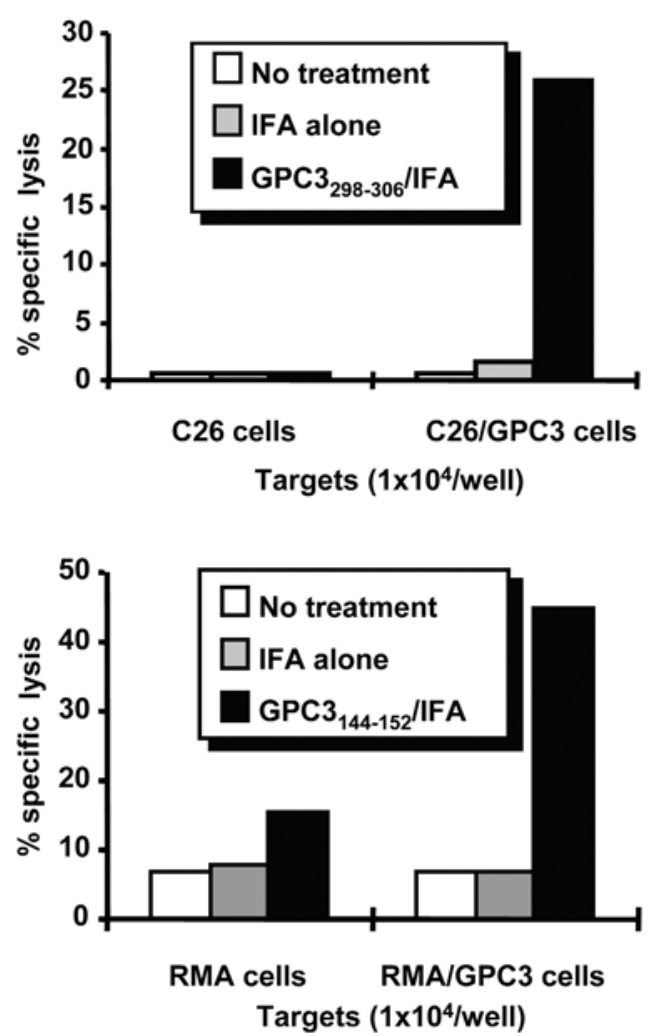

Figure 6. Cytotoxity of $\mathrm{CD} 8^{+} \mathrm{T}$ cells primed with GPC3 peptide vaccine. $\mathrm{BALB} / \mathrm{c}$ or $\mathrm{C} 57 \mathrm{BL} / 6$ mice $(\mathrm{n}=2-3)$ were vaccinated with IFA alone or $50 \mu \mathrm{g}$ peptide/IFA in the same manner as described above. The inguinal LN cells were cultured with $1 \times 10^{5}$ peptide-pulsed BM-DCs for 5 days. The cells obtained were sorted to the $\mathrm{CD}^{+} \mathrm{T}$ cell fraction with microbeads. Cytotoxic assays were performed with the cells to evaluate their capacity to kill $1 \times 10^{4} \mathrm{C} 26, \mathrm{C} 26 / \mathrm{GPC} 3$, RMA-HHD, or RMA-HHD-GPC3 cells. Data are representative of 3 independent experiments with similar results.

In 1996, Salgaller et al reported that they did not detect dose dependency between 1 and $10 \mathrm{mg}$ in the capacity of gp100 peptide to enhance immunogenicity in humans (9). A dose-dependent effect of peptide vaccine was shown in the present study. We are conducting a phase I clinical trail of GPC3-derived peptide vaccine in patients with advanced HCC at National Cancer Center Hospital East, and we are waiting for the results to determine whether a dose-dependent effect of peptide/IFA was shown in humans, the same as in the mouse model.

\section{Acknowledgments}

This work was supported in part by Health and Labor Sciences Research Grants for Research on Hepatitis from the Ministry of Health, Labor, and Welfare, Japan, and a grant-in-aid for the Third-Term Comprehensive 10-Year Strategy for Cancer Control from the Ministry of Health, Labour and Welfare, Japan. Foundation for Promotion of Cancer Research in Japan, Japan Research Foundation for Clinical Pharmacology and Research Resident Fellowship from the Foundation for Promotion of Cancer Research, Japan (Y.M.). We thank Junko Ashihara and Manami Shimomura for technical assistance.

\section{References}

1. Schwartz M, Roayaie S and Konstadoulakis M: Strategies for the management of hepatocellular carcinoma. Nat Clin Pract Oncol 4: 424-432, 2007.

2. El-Serag HB and Rudolph KL: Hepatocellular carcinoma: epidemiology and molecular carcinogenesis. Gastroenterology 132: 2557-2576, 2007.

3. Nakatsura T, Yoshitake Y, Senju S, et al: Glypican-3, overexpressed specifically in human hepatocellular carcinoma, is a novel tumor marker. Biochem Biophys Res Commun 306: $16-25,2003$.

4. Nakatsura T, Komori H, Kubo T, et al: Mouse homologue of a novel human oncofetal antigen, glypican-3, evokes T-cellmediated tumor rejection without autoimmune reactions in mice. Clin Cancer Res 10: 8630-8640, 2004.

5. Nakatsura T, Kageshita T, Ito S, et al: Identification of glypican-3 as a novel tumor marker for melanoma. Clin Cancer Res 10: 6612-6621, 2004.

6. Komori H, Nakatsura T, Senju S, et al: Identification of HLAA2- or HLA-A24-restricted CTL epitopes possibly useful for glypican-3-specific immunotherapy of hepatocellular carcinoma. Clin Cancer Res 12: 2689-2697, 2006.

7. Tagawa ST, Cheung E, Banta W, Gee C and Weber JS: Survival analysis after resection of metastatic disease followed by peptide vaccines in patients with Stage IV melanoma. Cancer 106: 1353-1357, 2006.

8. Mittendorf EA, Gurney JM, Storrer CE, Shriver CD, Ponniah S and Peoples GE: Vaccination with a HER2/neu peptide induces intra- and inter-antigenic epitope spreading in patients with early stage breast cancer. Surgery 139: 407-418, 2006.

9. Salgaller ML, Marincola FM, Cormier JN and Rosenberg SA: Immunization against epitopes in the human melanoma antigen gp100 following patient immunization with synthetic peptides. Cancer Res 56: 4749-4757, 1996.

10. Pascolo S, Bervas N, Ure JM, Smith AG, Lemonnier FA and Perarnau B: HLA-A2.1-restricted education and cytolytic activity of CD8(+) T lymphocytes from beta2 microglobulin (beta2m) HLA-A2.1 monochain transgenic $\mathrm{H}-2 \mathrm{Db}$ beta $2 \mathrm{~m}$ double knockout mice. J Exp Med 185: 204320-204351, 1997

11. Hattori K, Matsushita R, Kimura K, Abe Y and Nakashima E: Synergistic effect of indomethacin with adriamycin and cisplatin on tumor growth. Biol Pharm Bull 24: 1214-1217, 2001.

12. Senju S, Iyama $\mathrm{K}$, Kudo $\mathrm{H}$, Aizawa $\mathrm{S}$ and Nishimura $\mathrm{Y}$ : Immunocytochemical analyses and targeted gene disruption of GTPBP1. Mol Cell Biol 20: 6195-6200, 2000.

13. Niwa H, Masui S, Chambers I, Smith AG and Miyazaki J: Phenotypic complementation establishes requirements for specific POU domain and generic transactivation function of Oct-3/4 in embryonic stem cells. Mol Cell Biol 22: $1526-1536,2002$.

14. Motomura Y, Senju S, Nakatsura T, et al: Embryonic stem cell-derived dendritic cells expressing glypican-3, a recently identified oncofetal antigen, induce protective immunity against highly metastatic mouse melanoma, B16-F10. Cancer Res 66: 2414-2422, 2006.

15. Muneta Y, Nagaya H, Minagawa Y, Enomoto C, Matsumoto S and Mori Y: Expression and one-step purification of bovine interleukin-21 (IL-21) in silkworms using a hybrid baculovirus expression system. Biotechnol Lett 26: 1453-1458, 2004.

16. Miles AP, McClellan HA, Rausch KM, et al: Montanide ISA 720 vaccines: quality control of emulsions, stability of formulated antigens, and comparative immunogenicity of vaccine formulations. Vaccine 23: 2530-2539, 2005

17. Nava-Parada P, Forni G, Knutson KL, Pease LR and Celis E: Peptide vaccine given with a Toll-like receptor agonist is effective for the treatment and prevention of spontaneous breast tumors. Cancer Res 67: 1326-1334, 2007.

18. Kosaka A, Wakita D, Matsubara N, et al: AsialoGM1+CD8+ central memory-type $\mathrm{T}$ cells in unimmunized mice as novel immunomodulator of IFN-gamma-dependent type 1 immunity. Int Immunol 19: 249-256, 2007.

19. Iborra S, Carrion J, Anderson C, Alonso C, Sacks D and Soto M: Vaccination with the Leishmania infantum acidic ribosomal P0 protein plus $\mathrm{CpG}$ oligodeoxynucleotides induces protection against cutaneous leishmaniasis in C57BL/6 mice but does not prevent progressive disease in BALB/c mice. Infect Immun 73: 5842-5852, 2005. 